\title{
Leoncio Guerrero
}

\section{El Maule y Mariano Latorre}

\section{EL PUERTO}

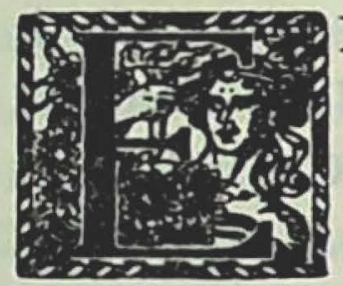

XISTE en el centro de Chile un puerto menor, antaño, mayor, que se llamó Nueva Bilbao porque sus fundadores, Oñederra, Barazarte y otros, así lo bautizaron en homenaje a su tierra natal: Bilbao, del país vasco. Este puerto, que más tarde la acuciosidad oficialista rebautizaría con la ambigua palabra de Constitución, se halla ubicado en la orilla izquierda del ancho estuario que en la desembocadura forma, en conjunción con el mar, el legendario y antaño también caudaloso río de las nieblas o Maulelfu.

Allí se desarrolló una industria que dió vida y color al puerto: me refiero a la carpintería de ribera. De sus numerosos astilleros han salido lanchas, faluchos, balandros, veleros y vapores. Los jesuítas fundaron el primero de estos astilleros para aprovechar los enormes bosques de roble pellín, cuya madera, resistente al agua y a los años, es apropiada para rodas, cuadernas y quillas. Con estos elementos - belleza, industria, esfuerzo - se formaría también un tipo de hombre un tanto ensoñador, intrépido y sufrido: el maulino. El maulino pescador, patrón de lancha, guanay o barquero, obrero de ribera, etc.

Es y era apasionante bajar al río y escuchar el ruido de martillos y combos, clavando las cuadernas o calafateando las uniones de las tablas. Toda esta actividad humana enmarcada por verdegueantes ce. 
rros y una bruma impalpable que sume el ambiente en una extraña aura de misterio.

Más allá, detrás del cerro Mutrún, está el mar en lucha perpetua con una nefasta barra de arena que ha ido aniquilando lentamente el progreso del puerto.

Al otro lado del río, relampaguean los vidrios de las casas y bodegas de Quivolgo, en los atardeceres.

Hacia arriba, navega la neblina, que va oculta de las viñas y poblados con nombres de eufonía indígena: Maquehua, Huinganes, Pichamán, Rauquén.

De cuando en cuando, la neblina se levanta y deja entrever caminos agrestes culebrear y perderse por entre los cerros de la Cordillera de la Costa, hacia Nirivilo, Empedrado, Purapel.

En la ciudad vive una sufrida población, formada de españoles, ingleses, franceses, alemanes, italianos, descendientes de "vaporinos" o marineros y oficiales de barcos que, atraídos por la personalidad y belleza de las maulinas, desertaron y anclaron sus vidas allí. Son muchos los nombres de estos extranjeros que han dado lustre a sus apellidos: Mac-Iver, Donn, Marshall, Schepeller, etc.

\section{LAS SENSACIONES}

Latorre nace en Cobquecura, una aldea perdida por las serranías de la costa. Fué llevado, niño, a Constitución. Desciende de "un bello vasco", como él lo declara, y de una dama de apellido Court, hija de un armador del puerto. El "bello vasco" no sabe ganar el dinero y luego cae en bancarrota, por lo que, después de su muerte temprana, la madre y los hijos tienen que refugiarse en casa del abuelo. Imaginemos a Mariano niño, vestido con unos pantalones cortos de borlón y una blusilla azul, desteñida a manchones por el poderoso sol de la costa. Es un chico pálido, delgado. Su rostro está tostado por el viento del mar. Pero es un niño inquieto, observador. Le atrae principalmente el río. Allí juega con pequeños barcos y veleros que él mismo se ha construído con la blanda madera de cardón o puya. 
Con la mitad del cuerpo en el agua, empuja sus veleros hacia el centro de la corriente. A veces riñe con algún compañero que le hunde el barquichuelo de una pedrada.

Vaga por la ribera con otros muchachos, después de la salida del liceo. Boga en pequeños y livianos botes. Suelen aventurarse hasta la barra donde sortean las grandes olas que penetran por la boca. Esta proeza ha costado la vida a más de alguno de sus amigos y él ha vivido dramáticos momentos en los naufragios.

También van de exploración por las oquedades de la costa. Conocen al detalle todas las rocas y sus vericuetos. La Piedra de las Ventanas, la de los Enamorados, Calabocillos, la Piedra de la Iglesia. Esta última ha de impresionarlo por su tamaño y extraña conformación. Hasta su ojo de luz se llega por un caminillo abierto en la roca. Se trepa a saltos, a riesgo de resbalar y caer a las hirvientes aguas del mar que, abajo chocan, saltan, se arremolinan. El niño no ha de olvidar el colorido del techo que forman los rezumos calcáreos.

Deambula por las inmensas playas de arena negra. Se tiende voluptuosamente a presenciar una puesta de sol y a sugerirle formas. Ya es una lámpara, o un florero, o un jarrón. El mar cada vez se acerca más a él. Hasta que termina por alcanzarlo. El huye insultándolo y lanzándole arena. De esta suerte sigue el rito: excitar al océano para que se lance de nuevo a alcanzarle.

Pero donde gusta más de estar largas horas, es en la Poza, un lugar entre el Mutrún y el río. Allí deja vagar su vista. Pasan botes a remo que vienen de Quivolgo hasta el Pasaje. Llegan lanchas cargadas de rodelas de leña, o de pipas, o de sandías y carbón. Vienen de Linares de Perales, en la confluencia del Claro con el Loncomilla. Los guanayes o lancheros las arrastran a la sirga. Sus gritos alargados llenan de vida la Poza. Sudorosos bajo sus cotonas blancas, caminan largos trechos sobre las piedras enlamadas.

En el centro del río están anclados el "Elvira" y el "Horacio", barcos de gran calado. 
De pronto, un grupo de muchachos, irrumpe en la Poza. Empiezan a lanzar piedras al mono de bronce que representa al Dios de los comerciantes y de los ladrones, el Dios Mercurio, con sus tobillos alados, que allí han puesto las pretensiones culturales de los prohombres maulinos.

Los rapaces lanzan certeras pedradas que dan en las mártires formas de bronce. Rebotan con un ruido metálico y caen al río. A veces, arrastran con ellas trozos de bronce, con gran contentamiento de los bárbaros. Mariano se une a ellos y acierta más de una pedrada. Este es un entretenimiento cotidiano, de generaciones. Mariano abandonó el Maule cuando el Mercurio estaba destruído hasta la cintura. El que habla tuvo el honor de haber contribuído a volar las alas y los pies del pretensioso monumento. ¡Oh, larga y cruel agonía de un Dios!

La carpintería de ribera entusiasma al muchacho. Está presente en el astillero desde que se monta una quilla, hasta la botadura del falucho. Conoce todas las piezas, sus nombres y su ensambladura. Por eso admira al "abuelo", un maniático vasco-francés para quien no hay secretos en la construcción de barcos y que lleva el mar en su sangre. Por la casa hay diseminados trozos de velamen, de bauprés, de cuadernas. El olor a brea es el mayor estímulo para su fantasía de muchacho. Tampoco olvidará "un buque de tres palos, encerrado en una botella”, y dibujos y croquis de embarcaciones, construídos en los astilleros de la familia y que, después, naufragaron en alguna parte del litoral.

Pero quien atrae poderosamente su atención es Aquiles Elliot.

Ese sí que es un verdadero "hijo del Maule". Un fornido y hermoso tipo masculino que atrae a las mujeres y de quien se ha enamorado una prima suya, fina y delicada. El no la toma en cuenta, pues tiene de amante una bravía hembra de la tierra. Este Aquiles Elliot es, además, "un marino antiguo, robusto, algo pirata, enamorado del mar y de su buque". Un día concibe la idea de reflotar un velero, semisumergido en la "sangre" del fango. El no tiene medios, pero los tiene el abuelo de quien no es fácil substraerlos. El problema consiste en interesarlo. Mariano interviene para ayudar a su héroe. Pero lo 
hecha todo a perder. Mas, sucede algo inaudito: acoge la aventura la esposa del abuelo, una mujer "ordinaria", malquerida en la familia. Aquiles está feliz, después de tantos desalientos. Por fin va a ser dueño y capitán de un barço, viejo sueño de aventurero. Reflota el arruinado velero, lo repara, lo apareja, lo pinta, hasta convertirlo en un flamante barco, blanco, gallardo. Un día es arrastrado más allá de la barra y enfila proa en dirección a Valparaíso, llevándose al propio Mariano, medroso, pero feliz. Aquiles lo desembarca allá en el puerto y luego él parte en su goleta hacia rumbo desconocido. Este viaje por mar del futuro autor, marca una etapa en su vida. Jamás lo olvidará. Siempre estará narrándolo y recordando episodios. Por ejemplo, aquellas hallullas tostadas en rescoldo de arena y masticadas lentamente mientras la lancha cabecea en la hora tranquila del atardecer. Se comprende, entonces, esta emoción del mar, esta delectación por la ola, por la gaviota, por el casco de un velero.

\section{LA EMOCION}

La adolescencia trae nuevos problemas: las relaciones sociales y el amor. El pueblo chico exagera siempre estas situaciones. ¡La gente es muy observadora!

Mariano ya ha salido del terruño. Ha estado en Talca y en Santiago. Ya tiene experiencia. Se ha desprejuiciado un tanto y observa con ojos burlones las cursilerías de sus conterráneos. Asiste a reuniones sociales. Recoge de la abuela narraciones como aquella del jilguerillo de Miss Elliot. Es ésta una solterona romántica que aún piensa que no han pasado los años y se comporta como una muchachuela. Sucede que en un casamiento, al partir la torta, salen volando unos jilguerillos que los galantes marinos asistentes se apresuran a aprisionar para obsequiárselos a la galante jamona. Pero uno de los jilguerillos desaparece. Imposible encontrarlo. Mas, cuando ella, un tanto desencantada, llega a su cuarto y se desviste la rígida crinolina... la avecilla sale volando de su cálido refugio... El autor habrá de utilizar este tema con gracia, frescura y agilidad. 
Por lo demás, Mariano ha de burlarse siempre de sus parientes. Es una burla con sangre, reconcentrada. Lleva un gran rencor que él no se recata en declarar. Quiere que se sepa que el abuelo menospreció a su padre y no tuvo las atenciones económicas que debía a su hija viuda. Odió a la segunda esposa del abuelo y a toda su familia. Los llama con epítetos ridículamente crueles, con esa causticidad pintoresca en que fuera maestro.

Esta causticidad habría de costarle el exilio de su querido mapu o tierra de su infancia. Vive allí un personaje influyente que, según dicen, se hizo rico en las famosas minas de Putú, un lugarejo del otro lado del río. Este personaje prometió hacerlo matar si veía la odiosa figura de Mariano por el pueblo de Constitución. Y él lo tomó en serio. Más de una vez me propuso acompañarme al Maule, de incógnito. Nunca se realizó este anhelo. Pero permanentemente estaba inquiriéndome noticias sobre la vida actual de la región. A pesar de los años de ausencia, él no había olvidado nada de los rincones, de las calles, de la orilla, de las rocas. Mas jay! en la imaginación de Mariano Latorre quedaba un puerto ideal que ya no existe. El no vió, por ejemplo, esa barbarie de ingeniería que construyó un puerto en seco, matando todas las esperanzas de los maulinos de volver a ser ese Puerto Mayor del cual estuvieron tan orgullosos.

El abuelo no quiere a estos hijos del "bello vasco". Los siente lejos de sus pequeñas preocupaciones materiales. $Y$ no adivina el cariño que este nieto tiene por el puerto. Agréguese a este despego, el hecho inaudito que este joven no estudiase con el empeño que él hubiera querido, las leyes que habrían venido a dar lustre a la familia. No. Por el contrario, este jovenzuelo se dedica a escribir versos y a llevar, en Santiago, una vida bohemia. Para colmo, este imberbe atildado se enamora de una fina jovencita y le escribe versos. ¡Versos! ¡Imagínense! Estar educando a este jovenzuelo para que garabatee tonterías. 


\section{EL ESCRITOR}

Es por esta época cuando Mariano encuentra su verdadera vocación. Todo aquello que ha visto y ha sentido tan profundamente no puede quedar encerrado dentro de sus recuerdos. Debe ser transmitido para que se conozca esta belleza humana y natural. ¡Lo escribirá! Es un descubrimiento. Ha leído autores rusos, franceses y españoles y éstos le han enseñado que el medio proporciona la materia literaria a aquellos que tienen la sensibilidad suficiente para cogerla. Es el realismo estilizado que había de dar a Mariano la satisfacción de unir su inquietud artística y su cariño al terruño, creando una realidad ideal y trascendente, abriendo una huella literaria.

Por esta etapa le interesan el hombre y sus problemas, sus dramas y sus heroísmos. En suma, la epopeya de sus vidas, lo que unido a las fuertes vivencias de su infancia, había de crear esa maciza y definitiva obra que nos deja.

El joven ahora observa a conciencia. Busca al pescador, al lanchero en sus faenas. Sufre con ellos el surazo de las noches. El viento "tiene una enorme fuerza: sus ráfagas resbalan sobre la piel curtida de los pescadores como sobre la algosa piel de las peñas" recuerda.

Se hace camarada de personajes como "El Americano" y de la Carmen, alma de la colonia de pescadores, "con enmarañada cabellera de tintes rojos; su carota tosca y bonachona, su maciza estatura de hembra fornida"...

Esta guapa hembra yo la conocí, ya vieja y mendiga, desprovista de toda aquella gallardía sensual de la época de Latorre.

Para Mariano la vida del Maule es una fiesta permanente. Botadura, bautizo de goletas, partida de faluchos y lanchas cuando la caprichosa barra se permite abrir sus arenas para dar paso a la negra quilla de estas naves.

El falucho es una embarcación tosca, cuya originalidad consiste en tener dos proas para hacer más fácil la maniobra del remolque. 
Estos faluchos, al mando de un patrón y tres marineros, navegan por nuestras costas a pura vela y a pura valentía. Van más allá de Valparaíso, Taltal, Iquique. Algunos son entregados en puertos como el Callao, San Francisco de California. Sus viajes son toda una odisea para estos "chilenos del mar", impertérritos ante los peligros, de alma bondadosa y cordial ademán.

Por otra parte, es interesante el paisaje en M.riano Latorre.

El paisaje y sus elementos penetran muy hondo en su retina. No se sabe cuándo el paisaje se humaniza o el hombre se hace, a su vez, paisaje.

Hay que destacar otro aspecto. Las sombras no son negras, sino que brillan en todos los matices. Hay en sus obras una permanente interrelación entre la plástica y la literatura.

Por ejemplo, dice: "Un poco más allá, la corriente se deshacía entre los mil pedruscos del lecho en una sábana crespa y murmuradora; la cerca del potrero estaba rota, y por la gran puerta divisábase un trozo de campo verde, galegas que habían invadido las márgenes del arroyo y manchaban el color obscuro de la tierra, recién removida en el verde claro de sus hojas nuevas, un gran cuadro de hortaliza y luego filas interminables de álamos, rectos, altos y en cuyas copas esbeltas solía respirar el vino encarnado del quitral, y, a través de ellos, el cielo celeste del mediodía”. Un verdadero cuadro del campo, de estilo impresionista a manchas yuxtapuestas.

Esta cualidad pictórica se hace aún más vivaz cuando enfoca una marina. "Un vapor, escribe, alejándose de la barra, desenredándose el humo en largos flecos negruzcos, en el desteñido fondo celeste de la tarde; la mitad del cuadro ocupábala el mar, al cual su imaginación prestábale vida y colorido: lo veía verde y movible... soñando en lejanos viajes".

Su primer libro Cuentos del Maule, publicado en 1912 (44 años a la fecha, casi medio siglo) en los talleres de la Empresa Zig-Zag, con un subtítulo sugestivo entre paréntesis, (Tipos y Paisajes Chilenos), es la más fresca y vivaz de sus obras. Allí está el despertar de un espíritu sensitivo, en medio del paraíso. 


\section{OTROS RINCONES}

Latorre, siguiendo la huella de la neblina, subió, por el río y se interna por las serranías de la Cordillera de la Costa, cuya topografía está formada por cerros y pequeños valles. Verdaderos rincones. Es. tuvo en Nirivilo, Chanco, Purapel. En aquellas abandonadas regiones parece que nadie pudiera subsistir. Sin embargo, están pobladas de una numerosa y original raza en decadencia, resultante de la consanguinidad. Esto, a su vez, explica la gran cantidad de tarados de alma torva, que por esas tierras pululan. Son tierras pobres, similares a las de González Bastías, gran amigo de Latorre. El sol calcina los polvorientos caminos y la sequía de los estíos es el azote de un Dios despiadado. Hay años de hambre y de miseria en que los lugareños tienen que comerse sus bueyes de labor y sus caballos. Pero no emigran. Se quedan adheridos a sus pequeñas hijuelas, a sus primitivos prejuicios y a sus tradiciones religiosas, semipaganas, que no pueden cambiar los curitas que, a la vez, son conquistados por el medio y se quedan allí olvidados. Se hacen campesinos, cultivan viñedos y beben con fruición del estimulante y grueso mosto de las cepas de rulo.

De esas regiones, Latorre extrae la materia para On Panta, Zurzulita, Hombres y zorros.

$\mathrm{Y}$ es verdad. Son hombres astutos y desleales, como el animalito ladrón de gallinas. Es interesante el tipo de bandido de la región. Todos los hombres son salteadores en potencia. Alternan las salidas con el trabajo honrado. Hay otros que sólo se dedican al cuatrerismo, es decir, al robo de animales, que, después, arrean hacia otras regiones. Prototipo de este cuatrero bandido fué Domingo Persona, quien no podía morir, porque, según la tradición, tenía "un Santo Cristo encarnado que lo protegía”. Sobre este personaje escribió Latorre uno de sus mejores cuentos.

On Panta es el huaso del lugar, sórdido, decadente, a quien idiotiza una obsesión. Conserva embalsamado el puma que cazara en su 
juventud. Un día, irreverentemente, los perros se lo atacan y despanzurran.

La novela Zurzulita es un fuerte episodio de amor y de odio, de violencias y asesinatos. Describe la vida de Purapel, aldehuela perdida entre las ásperas serranías de la provincia del Maule.

\section{RIO ARRIBA Y VAGANCIAS}

Mariano Latorre continúa por la ruta del río, la ruta de las lanchas y de los guanayes. Pasa el valle. Conoce la hermosa laguna que da origen al Maule. Por allí deambula y observa. Fruto de esta época es su libro Cuna de cóndores. En sus páginas encontramos la pequeña vida de los hombres de la cordillera de los Andes, en permanente lucha con la nieve, los pumas, los cóndores y las "risqueras vanas", que acechan en cada vuelta de los senderos.

Posteriormente, Latorre sigue el impulso del maulino: vagabundea por Chile. Se hace "pata de perro", según la pintoresca expresión del lugar. Mas, vaga siempre en función de hijo del Maule, en una permanente actitud de comparación. Le atrae Chiloé, porque en ella hay un ambiente de ensueño, como en su río y los hombres son marinos de sangre y viven para el mar.

Se le ve por las tierras magallánicas, por las costas de Arauco, por la desembocadura del Maullín, por los lagos del sur.

Pero no quiere salir al extranjero, porque, hombre de rincones, le teme al horizonte.

\section{MARIANO LATORRE Y SU ESTATUA}

Esta fueron las relaciones de Mariano Latorre con el Maule, la tierra de su alma. La inmortalizó con su talento. Cumplió con el Maule, y cumplió con creces. Los hombres del Maule le deben su orgullo de ser personajes de novela.

Por otra parte, las letras chilenas, le deben su valentía para abrir una brecha, un camino literario. Fué un pionero como aquellos otros 
vascos que fundaron un puerto en la desembocadura. Por este sendero avanzan las nuevas generaciones, para quienes los temas están a su alrededor, vida realizándose.

Mariano Latorre coge la vida, su drama, su lucha y el ambiente en que los personajes se desenvuelven. Destaca con deleite, sin duda, la epopeya de ese rincón de sus años mozos y la muestra aderezada. En esto hay una intención social. Acusa el abandono y desconocimiento en que se tiene a esos hombres esforzados, vigorosos, dignos de mejor suerte.

Chile, ha dicho el escritor, como en una síntesis de sus viajes, es un país de rincones. Rincones de la cordillera, del valle, del río, de las caletas. Rincones del norte minero y salitrero y del sur lacustre y austral. En cada uno de ellos se ha formado un ser humano con características originales; o recio, o ladino, o solapado, o generoso, o aventurero. Sin embargo, estos entes son variaciones del roto, ese roto que Latorre amara y exaltara como una antítesis de su propia persona, europea y refinada.

Recojamos su mensaje. Escribamos las novelas de nuestros rincones. No importa la técnica, ni que nos digan que pertenecemos a ésta - aquélla tendencia. Lo importante es escribirlas con talento y con fuerza. Serán obras vitales, no gemidos conceptistas e intrascendentes.

Mariano Latorre se ha erigido su propia estatua. Pero yo propondría que se le levantara una de bronce, en reemplazo de aquella de Mercurio, destruído a pedradas por los niños vengadores del Maule, y que se ubicara allí en la Poza, en ese rincón evocador y de ensoñación, en donde el escritor fuera a mirar la lucha permanente entre el río y el mar. 